\title{
Characterization of Cooperative Breeding for the Buff-throated Partridge (Tetraophasis szechenyii) Based on Parentage Testing
}

\author{
Qin Liu ${ }^{1,2}$, Bin Wang ${ }^{1,3}$, Yu Xu ${ }^{1,4}$, Xiuyue Zhang1, Tao Zeng1* and Jianghong Ran ${ }^{1 *}$ \\ ${ }^{1}$ Key Laboratory of Bio-Resource and Eco-Environment of Ministry of Education, \\ College of Life Sciences, Sichuan University, Chengdu 610065, Sichuan, P.R. China \\ ${ }^{2}$ College of Life Sciences and Food Engineering, Yibin University, Yibin 644007, P.R. \\ China \\ ${ }^{3}$ Institute of Ecology, China West Normal University, Nanchong 637002, P.R. China \\ ${ }^{4}$ School of Life Sciences, Guizhou Normal University, Guiyang 550001, P.R. China
}

\begin{abstract}
A B S T R A C T
The buff-throated partridge (Tetraophasis szechenyii), a sexually mono chromatic Galliformes species, is an endangered bird endemic to western China. Previous studies suggested that it had the behavior of facultative cooperative breeding, which was rarely reported in Galliformes. In this study, we isolated 17 tetra-nucleotide microsatellite loci to test parentage and kinship for a wild population with 29 individuals from 10 different families (A-J). The 17 loci with the mean polymorphic information content (PIC) of 0.566 and the combined probability of exclusion for the second parent $(\mathrm{CPE} 2=99.98 \%)$ met the minimum standard of international human paternity test. Among all 18 identified birdlings and helpers, bi-parents of eight offspring were successfully inferred and single parents of seven offspring were inferred at a confidence level of $95 \%$. Except helper $\mathrm{H} 1$ without valid parents detected, the remaining six helpers were inferred to be at least single parents. The mean relatedness of nine females $(0.08554 \pm 0.01041)$ was smaller than that of 20 males $(0.10243 \pm 0.02838)$. The results showed: 1$)$ cooperative breeding families might have one or more helpers, which were philopatric offspring, or were foreign individuals without kin relationship, or both; 2) both male and female could serve as helper, although male helpers seemed to be more, which were six times than the females in present study; 3 ) it was preliminarily inferred that femalebiased dispersal existed in this study group; 4) inbreeding and extra-group paternity (EGP) were detected.
\end{abstract}

\author{
Article Information \\ Received 27 November 2019 \\ Revised 02 January 2020 \\ Accepted 24 January 2020 \\ Available online 19 March 2021 \\ Authors' Contribution \\ QL, TZ and JR designed the study. \\ BW and YX collected specimens. \\ QL conduct the research work and \\ wrote the manuscript. YX, XZ and JR \\ revised the manuscript. \\ Key words \\ Birds, Kinship analysis, Reproductive \\ strategies, Tetra-nucleotide \\ microsatellite
}

\section{INTRODUCTION}

$\mathrm{C}$ ooperative breeding is one of reproductive system in which more than a pair of individuals raises young from a single nest or blood (Brown, 1987; Cockburn, 2006). This system encompasses diverse social and mating relationship; for example, breeding pairs exhibit helpers and various forms of cooperative polygamy (Brown, 1987). Cooperative breeding occurs in some birds, mammals and fish, but is more common in birds and has been studied more deeply, which is closely related to life evolutionary history and behavioral adaption of birds (Canestrari, 2008). Therefore, the study of this behavior has been one of hotspots in ornithology ecology, and intensive efforts have been done (Pravosudova et al., 2001; Vehrencamp and Quinn, 2004; Ekman and Ericson, 2006;

\footnotetext{
* Corresponding author: rjhong-01@163.com; zengtao_ slt@163.com

0030-9923/2021/0003-0903 \$ 9.00/0

Copyright 2021 Zoological Society of Pakistan
}

Meade and Hatchwell, 2010; Covas et al., 2011; Wang and Lu, 2011; Preston et al., 2013; Koenig and Walters, 2016).

According to phylogenetic studies based on the assumption of biparental care, cooperative breeding is inferred to occur in $9 \%$ of bird species, and has genealogy conservatism, which occurs in clusters in phylogenetic tree (Cockburn, 2006; Hatchwell, 2009). Previous studies showed cooperative breeding was very common in altricial in Passeriformes, while was rare in precocial birds, such as Galliformes, which did not have broad demand for parental care because of their relatively large body size. Until recent, several cooperative breeding cases were reported in the order Galliformes (Lu and Zheng, 2005; Hale, 2006; Xu et al., 2011; Zeng et al., 2016). Although, additional cases are generally very rare, they are crucial for understanding the patterns and evolutionary mechanisms of cooperative breeding (Ligon and Burt, 2004).

The buff-throated partridge (Tetraophasis szechenyii), which is a unique endemic species to southwest China, is a medium-sized sexually monochromatic bird in Galliformes. Although it is listed as a LC (least concern) 
species by the IUCN red list, the species is threatened by hunting and habitat fragmentation. Thus, it has been listed as "category I state protection" in China. It mainly occurs in mixed coniferous forest, rhododendron shrubs, oak thickets, alpine meadows, and rocky ravines at high elevation (3350-4600m) (MacKinnon and Phillipps, 2000; Madge and McGowan, 2002). Based on field observations and studies, facultative cooperative breeding behavior has been reported in T. szechenyii (Xu et al., 2011; Yang et al., 2016). During the entire breeding season, helpers exhibit efforts behaviorally in terms of brooding, vigilance, and territorial display, including calling and fighting, but they also predominately engaged in territorial aggression more often than the breeding pair (Xu et al., 2011). However, due to the limitation of means in field work, many fundamental and crucial questions have not been clearly explained in the cooperative breeding system. For example, it was not clear whether the helpers could be offspring from delayed diffusion or foreign families, or both. And whether there is kinship between the foreign helpers and bi-parents? If the foreign helper is non-relatives, is there an extragroup paternity in the group? If the helper is close relative stayed in the nest, is there a phenomenon of inbreeding? In addition, significant sex-bias of helpers has been observed in sex composition, and it is usually male-bias (Koenig et al., 1996). It may be a non-selection additional phenomenon of female-biased dispersal (Greenwood, 1980). Thus, whether male-biased sex composition of helpers and female-biased dispersal are also present in $T$. szechenyii.

Here, we screened 17 microsatellite markers with high resolution using the next generation sequencing method to explore the characteristics of cooperative breeding for $T$. szechenyii. We aimed to explore the source of helpers, that was, to confirm the relationship between breeding pairs and helpers. Meanwhile, we tented to explore the possible relationships between helper's sex ratio composition and dispersal characteristics, to detect the risk of cooperative breeding, which could contain inbreeding and extra-group paternity, which providing some theoretical reference for the evolutionary mechanism of this behavior. Our studies will provide a certain direct evidence for cooperative breeding strategy and behavioral characteristic of $T$. szechenyii at molecular level.

\section{MATERIALS AND METHODS}

\section{Study animals}

The wild buff-throated partridges we studied were from Pamuling Mountain (PML), Yajiang County, in western Sichuan Province of China. During three years field work (2006-2008), we captured partridges using funnel-traps baited with rice in either the early or late breeding season. Blood samples were collected from 29 individuals and preserved in blood buffer at room temperature. We supposed that all individuals were active in the same nest for the same family, and the 10 families were named as A-J accordingly (Table I). In each family, the identification of every individual was determined using binoculars and followed from a distance recording the general behavior attributes. Based on field observation on morphological characteristics, the 29 samples were identified as 11 adult males, seven adult females, and 11 birdlings (Table I). For families with helpers, the social status of adult members was determined by their spatial distribution and interactions when foraging food (e.g., pecking, chasing, and escaping behavior). Along the highto-low dominance hierarchy, males and females were described as $\delta^{\Uparrow} 1, \widehat{\partial} 2, \delta^{\Uparrow} 3$, etc., and $+1, \circ 2, q 3$, etc. The $\delta^{\Uparrow} 1$ and $P 1$, which usually kept in close contact with each other while foraging, were referred to as the breeding pair, and the others were referred to as the helpers (Xu et al., 2011).

\section{Sex identification of birdlings}

Since it was difficult to identify the sex of birdlings only by field observation, we had adopted a molecular method to verify. For birdlings, PCR (Polymerase chain reaction) amplification of the female-specific gene HINTW (Histidine Triad Nucleotide Binding Protein) on the $\mathrm{W}$ chromosome was performed, and individual's sex was determined by the presence or absence of PCR products (Handley et al., 2004). As supplementary, we chose universal primers to amplify the $\mathrm{CHD}$ (Chromo Boxhelicase DNA Binding) gene and used the $\mathrm{Z} / \mathrm{W}$ chromosome length differences to identify the sex. In other words, the amplification results of male individuals showed a single band while the female individuals had two different length target bands (Zhou et al., 2008). The primers used were 2550F:5'-GTTACTGATTCGTCTACGAGA-3', 2781R:5'ATTGAAATGATCCAGTGCTTG-3' for CHD gene (Griffiths et al., 1996) and hintwF: 5'-AAGAGGGCTTGGGGTTTT-3', hintwR: 5'-CCAGGTTAGCAGCACT-3' for HINTW gene (Handley et al., 2004), respectively. The PCR reaction mixture had a final volume of $10 \mu \mathrm{L}$, which contained $0.3 \mu \mathrm{L}$ DNA (50ng/ $\mu \mathrm{L}), 5 \mu \mathrm{L} 10 *$ PCR buffer (plus Mg2+), $0.3 \mu \mathrm{L}$ dNTPs $(10 \mathrm{mmol} / \mathrm{L}$ each), $0.3 \mu \mathrm{L}$ for each primer $(10 \mathrm{mmol} / \mathrm{L}), 0.5 \mathrm{U}$ rTaq DNA polymerase (Takara, Japan),

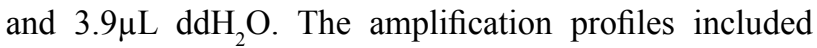
an initial denaturation at $95^{\circ} \mathrm{C}$ for $5 \mathrm{~min}$, followed by 35 cycles 30 s at $94^{\circ} \mathrm{C}, 45 \mathrm{~s}$ at $55^{\circ} \mathrm{C}, 45 \mathrm{~s}$ at $72^{\circ} \mathrm{C}$, and a final extension for $10 \mathrm{~min}$ at $72^{\circ} \mathrm{C}$ (Zhou et al., 2008).

\section{Microsatellite loci screening}

Genomics DNA of 29 buff-throated partridges were 
extracted from blood or feather using E.Z.N.A. Tissue DNA Kits (Omega, USA). We selected 16 loci that were previously screened by our research group through nextgeneration sequencing, and used the same method to isolate an additional locus and scan all 29 individuals (Table II). The PCR reaction mixture had a final volume of $25 \mu \mathrm{L}$, which contained $1 \mu \mathrm{L}$ DNA $(50 \mathrm{ng} / \mu \mathrm{L}), 2.5 \mu \mathrm{L} 10 * \mathrm{PCR}$ buffer (plus $\mathrm{Mg}^{2+}$ ), $1 \mu \mathrm{L}$ dNTPs $(10 \mathrm{mmol} / \mathrm{L}$ each), $0.5 \mu \mathrm{L}$ for each primer $(10 \mathrm{mmol} / \mathrm{L}), 0.5 \mathrm{U}$ rTaq DNA polymerase (Takara, Japan), and $18.7 \mu \mathrm{L} \mathrm{dd}_{2} \mathrm{O}$. The amplification profiles included an initial denaturation at $95^{\circ} \mathrm{C}$ for $5 \mathrm{~min}$, followed by 35 cycles $30 \mathrm{~s}$ at $94^{\circ} \mathrm{C}, 45 \mathrm{~s}$ at $58.0-65.7^{\circ} \mathrm{C}$, 30 s at $72^{\circ} \mathrm{C}$, and a final extension for $10 \mathrm{~min}$ at $72^{\circ} \mathrm{C}$ (see Table II for the optimum annealing temperature). For all candidate microsatellite loci, the 5'-end of the forward primer was fluorescently labeled (FAM, TAMRA or HEX), and successfully amplified products were added to $3.0 \mu \mathrm{L}$ methanamide and run in an ABI PRISM 3730 Genetic Analyser (Applied Biosystems Inc., Foster City, CA, USA). The analysis of allele sizes against the internal size standard and genotyped individuals was performed using GeneScan $^{\mathrm{TM}}-500$ LIZ $^{\mathrm{TM}}$ size standard and GeneMapper ${ }^{\mathrm{TM}}$ V4.0 software.

\section{Data analysis and paternity testing}

Numerical errors and null alleles were checked at $95 \%$ confidence interval using micro-checker (van Oosterhout et al., 2004). GENEPOP V3.4 was executed to test the Hardy-Weinberg equilibrium and the linkage disequilibrium (Raymond and Rousset, 1995). In order to assess the reliability of kin identification, the combined probability of exclusion for the first parent (CPE1, 1- Ne1p. see Table III for detail) and the second parent (CPE2, 1 - Ne-2p. see Table III for detail) of the 17 loci were calculated from allele frequencies using CERVUS V3.0.3 (Jamieson and Taylor, 1997; Kalinowski et al., 2007).

Paternity analysis was performed using program CERVUS V3.0.3, which was also used to estimate allele frequencies, observed and expected heterozygosities, and polymorphism information content (PIC) (Kalinowski et al., 2007). This program calculates the paternity inference likelihood ratio and generates a statistic variable, delta $(\Delta)$, defined as the difference in positive log likelihood ratios (LODs) between the top two candidate parent with known gender. If only one candidate parent with a positive LOD score exists, the delta value equals its LOD score. Based on observed allele frequencies, CERVUS uses a simulation to account typing error rates and incomplete sampling and determine the statistical significance of the delta value generated for each paternity (Marshall et al., 1998). CERVUS simulation parameters were set as follows: number of offspring $=10,000$, proportion of loci application $=1$, proportion of sample for candidate father and mother $=0.9$, rate of typing error $=1 \%$, relaxed confidence level $=80 \%$, strict confidence level $=95 \%$, proportion of loci typed depends on allele frequency analysis. If the number of genotypes that the offspring does not match the candidate parent is greater than two, the candidate parent will be excluded. Considering the actual situation of the need to understand helper source, this study combined individual sampling information such as gender and age, and we set out each need identification of offspring and all of the helpers and determine the corresponding candidate parent information in Supplementary Table S1.

\section{Coefficient of parentage}

For a reproduction population, estimation of the coefficient of parentage between individuals helps to determine their relationship and to test the results from paternity analyses. The coefficient of parentage is represented by the value of relatedness (r), which refers to the similarity of the genetic constitution between individuals in a group (Michod et al., 1980). We used software Coancestry V1.0 with TrioML estimator to calculate r (Wang, 2011). The relatedness between 29 individuals, the mean relatedness of the whole population, the mean relatedness of males and females, and the mean relatedness of different families and between families were calculated, respectively.

\section{RESULTS}

\section{Sex of birdlings}

The amplification products of the HINTW gene displayed that there were two bands for C2, C6, G1, $\mathrm{H} 2$ and no product for $\mathrm{C} 4, \mathrm{C} 5, \mathrm{D} 1, \mathrm{G} 2, \mathrm{H} 3, \mathrm{I} 1, \mathrm{I} 2$. The amplification test of the CHD gene consisted with it, displayed that there were $500 \mathrm{bp}$ and $750 \mathrm{bp}$ bands for $\mathrm{C} 2$, $\mathrm{C} 6, \mathrm{G} 1, \mathrm{H} 2$ and one single 500bp band for C4, C5, D1, G2, H3, I1, I2 (Supplementary Fig. S1). In other words, the former individuals were identified as females and the latter were males.

\section{Characteristics of microsatellites}

All 29 individuals were subsequently screened by 17 candidate tetra-nucleotide microsatellite loci. Using CERVUS V3.0.3 software to analysis, the number of alleles ranged from three to six (mean 4.47) (Table II). The observed and expected heterozygosity ( $\mathrm{Ho}$ and $\mathrm{He}$ ) varied from 0.379 to 0.862 (mean 0.574 ) and 0.479 to 0.818 (mean 0.631), respectively (Table II). The polymorphism information content (PIC) ranged from 0.390 to 0.774 with an average of 0.566 (Table II). There was no evidence for null alleles at $95 \%$ confidence interval. The distribution 
Table I. Basie information for Tetraophasis szechenyii samples at Pamuling.

\begin{tabular}{llll}
\hline Family & Individual information & Family & Individual information \\
\hline A & A1 (Male Helper, 2008) & F & E2 (Dominant Male, 2008) \\
& A2 (Dominant Female, 2008) & & F1 (Dominant Female, 2008) \\
B & A3 (Female Helper, 2008) & G & G1 (Male Helper, 2008) \\
& B1 (Male Helper, 2008) & & G2 (Male Birdling, 2006) \\
& B2 (Dominant Male, 2008) & & G3 (Dominant Male, 2006) \\
C & B3 (Dominant Female, 2008) & G4 (Male Helper, 2006) \\
& C1 (Dominant Female, 2007) & H & H1 (Male Helper, 2006) \\
& C2 (Female Birdling, 2007) & H2 (Female Birdling, 2006) \\
& C3 (Male Helper, 2008) & H3 (Male Birdling, 2006) \\
& C4 (Male Birdling, 2008) & I & I1 (Male Birdling, 2006) \\
& C5 (Male Birdling, 2008) & & I3 (Dominant Male, 2006) \\
D & C6 (Female Birdling, 2008) & & J1 (Dominant Male, 2006) \\
& D1 (Male Birdling, 2008) & J & \\
\hline
\end{tabular}

Note: 'Birdling' is the young bird in the current year. The numbers after comma in parentheses are the year of sample collection.

Table II. Polymorphism parameter and exclusion probability of 17 microsatellite loci of Tetraophasis szechenyii.

\begin{tabular}{llllllllll}
\hline Locus & Accession No. & Tm $\left({ }^{\circ} \mathrm{C}\right)$ & $\mathbf{k}$ & Ho & He & PIC & Size (bp) & $\mathbf{N}_{\text {e-1p }}$ & $\mathbf{N}_{\text {e-2p }}$ \\
\hline TSZ4 & KU236435 & 59.0 & 3 & 0.379 & 0.520 & 0.457 & $285-293$ & 0.870 & 0.728 \\
TSZ5 & KU236436 & 61.5 & 5 & 0.862 & 0.762 & 0.708 & $197-217$ & 0.658 & 0.479 \\
TSZ6 & KU236437 & 62.0 & 4 & 0.379 & 0.645 & 0.566 & $174-214$ & 0.793 & 0.644 \\
TSZ8 & KU236439 & 61.5 & 6 & 0.862 & 0.818 & 0.774 & $245-265$ & 0.571 & 0.393 \\
TSZ9 & KU236440 & 59.0 & 3 & 0.379 & 0.479 & 0.419 & $172-216$ & 0.889 & 0.757 \\
TSZ10 & KU236441 & 64.0 & 4 & 0.655 & 0.715 & 0.651 & $228-260$ & 0.715 & 0.546 \\
TSZ11 & KU236442 & 59.0 & 3 & 0.448 & 0.549 & 0.467 & $337-343$ & 0.855 & 0.726 \\
TSZ13* & MN862322 & 58.0 & 4 & 0.517 & 0.579 & 0.490 & $215-227$ & 0.835 & 0.707 \\
TSZ14 & KU236443 & 60.5 & 5 & 0.724 & 0.724 & 0.672 & $282-298$ & 0.696 & 0.516 \\
TSZ19 & KU236445 & 62.0 & 6 & 0.414 & 0.563 & 0.521 & $231-253$ & 0.826 & 0.655 \\
TSZ20 & KU236446 & 64.0 & 3 & 0.793 & 0.508 & 0.390 & $266-270$ & 0.876 & 0.796 \\
TSZ22 & KU236447 & 60.5 & 6 & 0.483 & 0.773 & 0.725 & $245-279$ & 0.631 & 0.450 \\
SCZ6 & KU236450 & 63.0 & 5 & 0.759 & 0.724 & 0.672 & $182-198$ & 0.695 & 0.515 \\
SCZ9 & KU236451 & 63.7 & 4 & 0.414 & 0.558 & 0.496 & $224-236$ & 0.845 & 0.695 \\
SCZ10 & KU236452 & 62.0 & 6 & 0.483 & 0.609 & 0.537 & $200-224$ & 0.808 & 0.658 \\
SCZ13 & KU236453 & 65.7 & 3 & 0.552 & 0.503 & 0.444 & $250-258$ & 0.878 & 0.737 \\
SCZ24 & KU236456 & 65.5 & 5 & 0.655 & 0.627 & 0.576 & $266-286$ & 0.786 & 0.613 \\
Mean & - & - & 4.47 & 0.574 & 0.631 & 0.566 & Combined & 0.01157523 & 0.00022641 \\
\hline N & & & 5 &
\end{tabular}

Note: Tm, annealing temperature of primer pair; $k$, the number of allele; Ho, the observed heterozygosity; He, the expected heterozygosity; PIC, the polymorphism information content; $\mathrm{N}_{\mathrm{e}-1 \mathrm{p}}$, average non-exclusion probability for one candidate parent; $\mathrm{N}_{\mathrm{e}-2 \mathrm{p}}$, the average non-exclusion probability for one candidate parent given the genotype of a known parent of the opposite sex.

*, newly isolated and submitted locus with primers F: 5'-ATTCAGAGCCAGGTTTGCTG-3' and R: 5'- GGCTTTGGAACTGAAACCCA-3'. 
Table III. Paternity test results for all larvae and helpers of Tetraophasis szechenyii.

\begin{tabular}{|c|c|c|c|c|c|c|c|c|}
\hline Offsp-ring & $\begin{array}{l}\text { Candidate } \\
\text { mother }\end{array}$ & $\begin{array}{l}\text { Mismatch } \\
\text { Loci }\end{array}$ & $\begin{array}{l}\text { Pair LOD } \\
\text { score }\end{array}$ & $\begin{array}{l}\text { Pair } \\
\text { confidence }\end{array}$ & $\begin{array}{l}\text { Candidate } \\
\text { father }\end{array}$ & Mismatch Loci & $\begin{array}{l}\text { Pair LOD } \\
\text { score }\end{array}$ & $\begin{array}{l}\text { Pair } \\
\text { confidence }\end{array}$ \\
\hline A1 & $\mathrm{A} 2$ & 1 & $2.65 \mathrm{E}+00$ & * & G2 & 1 & $2.84 \mathrm{E}+00$ & $*$ \\
\hline A3 & E1 & 4 & $-1.46 \mathrm{E}+01$ & + & $\mathrm{G} 2$ & 0 & $1.15 \mathrm{E}+01$ & $*$ \\
\hline B1 & $\mathrm{A} 2$ & 1 & $2.20 \mathrm{E}-01$ & $*$ & $\mathrm{I} 3$ & 3 & $-9.81 \mathrm{E}+00$ & \\
\hline $\mathrm{C} 2$ & $\mathrm{C} 1$ & 1 & $3.66 \mathrm{E}+00$ & $*$ & $\mathrm{C} 3$ & 0 & $9.98 \mathrm{E}+00$ & $*$ \\
\hline $\mathrm{C} 3$ & $\mathrm{C} 1$ & 1 & $3.40 \mathrm{E}+00$ & $*$ & $\mathrm{~J} 1$ & 0 & $3.44 \mathrm{E}+00$ & $*$ \\
\hline $\mathrm{C} 4$ & B3 & 0 & $1.13 \mathrm{E}+01$ & $*$ & $\mathrm{~J} 1$ & 0 & $5.42 \mathrm{E}+00$ & $*$ \\
\hline $\mathrm{C} 5$ & B3 & 1 & $1.04 \mathrm{E}+00$ & $*$ & $\mathrm{C} 3$ & 0 & $4.93 \mathrm{E}+00$ & $*$ \\
\hline C6 & B3 & 4 & $-1.09 \mathrm{E}+01$ & + & $\mathrm{C} 3$ & 2 & $-3.26 \mathrm{E}+00$ & $*$ \\
\hline D1 & D2 & 6 & $-1.99 \mathrm{E}+01$ & & G4 & 1 & $1.61 \mathrm{E}+00$ & $*$ \\
\hline $\mathrm{F} 2$ & A2 & 1 & $5.30 \mathrm{E}+00$ & $*$ & E2 & 2 & $-3.46 \mathrm{E}+00$ & $*$ \\
\hline G1 & D2 & 3 & $-7.12 \mathrm{E}+00$ & + & $\mathrm{H} 1$ & 3 & $-4.15 \mathrm{E}+00$ & + \\
\hline $\mathrm{G} 2$ & B3 & 5 & $-1.70 \mathrm{E}+01$ & & G3 & 0 & $1.02 \mathrm{E}+01$ & $*$ \\
\hline G4 & B3 & 3 & $-1.12 \mathrm{E}+01$ & + & G3 & 0 & $3.43 \mathrm{E}+00$ & $*$ \\
\hline H1 & E1 & 3 & $-1.19 \mathrm{E}+01$ & & I3 & 4 & $-1.33+01$ & \\
\hline $\mathrm{H} 2$ & E1 & 3 & $-1.24 \mathrm{E}+01$ & & $\mathrm{H} 1$ & 3 & $-9.56 \mathrm{E}+00$ & \\
\hline $\mathrm{H} 3$ & B3 & 1 & 8.73E-01 & $*$ & $\mathrm{H} 1$ & 1 & $3.04 \mathrm{E}-01$ & $*$ \\
\hline I1 & E1 & 2 & $-5.83 \mathrm{E}+00$ & + & $\mathrm{I} 3$ & 2 & 4.75E-02 & $*$ \\
\hline $\mathrm{I} 2$ & E1 & 1 & $1.68 \mathrm{E}+00$ & $*$ & $\mathrm{I} 3$ & 1 & $2.08 \mathrm{E}+00$ & $*$ \\
\hline
\end{tabular}

Note: *, strict confidence level at $95 \%$; , relaxed confidence level at $80 \%$; the bold italics font are the valid paternity identification results.

of alleles at all loci did not significantly deviate from the Hardy-Weinberg expectations $(\mathrm{P}>0.01)$, and all pairwise tests for linkage disequilibrium were also not significant ( $\mathrm{P}>0.001)$. The combined $\mathrm{N}_{\text {e-1n }}$ of 17 loci was 0.01157523 and the combined $\mathrm{N}_{\mathrm{e}-2 \mathrm{p}}$ was 0.00022641 (Table II). CPE1 of 17 loci was $98.843 \%$ when parent was unknown, and CPE2 was $99.977 \%$ when one of the parents was known.

\section{Paternity assignment}

In total, 18 individuals involving all of helpers and birdlings were performed for paternity identification. In all pairs of paternity test, there were 21 positive LOD values for candidate paternity varying from 0.0475 to 11.5 (Table III). Among them, nine individuals were identified for their genetic mother, and 12 individuals were identified for their genetic fathers. In addition, all parent-offspring identification results showed that the delta $(\Delta)$ values of 23 groups were at the strict confidence level $(95 \%)$ and six groups were at the loose confidence level (85\%). After excluding the groups with mismatch genotypes in more than two loci between parental and offspring, we successfully identified eight complete units of father-mother-offspring at the confidence level, which accounted for $44.44 \%$ of exampled individuals (Table III). In addition, seven identified individuals were inferred single parent at the confidence level, which accounted for $38.89 \%$ (Table III).

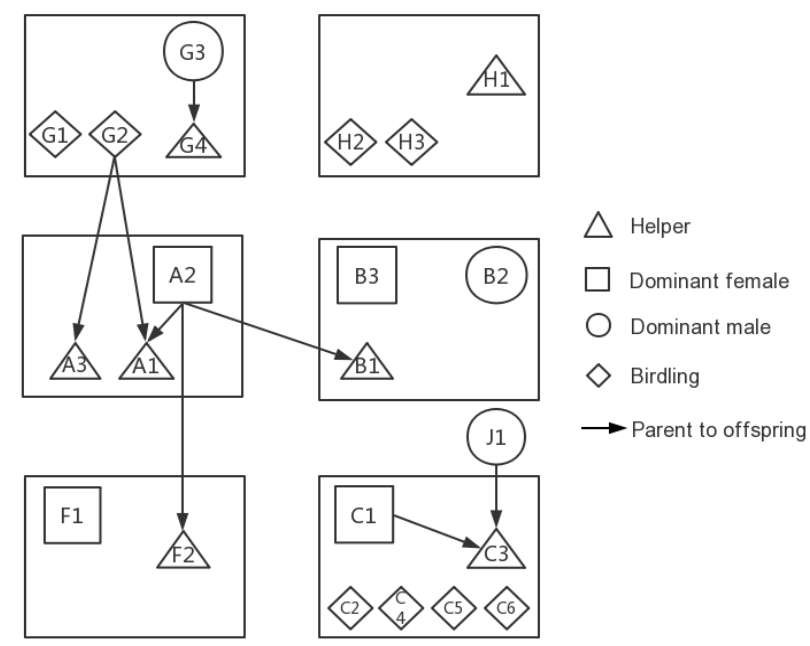

Fig. 1. Parentage of helpers in breeding group of Tetraophasis szechenyii.

Helper resource in different families was also inferred. In family $\mathrm{A}$, the male helper A1 was the offspring of the 
dominant female A2 and male G2 from another family. For the female helper A3, only G2 was detected as paternal source, but no maternal information was found. In family $\mathrm{B}$, the male helper $\mathrm{B} 1$ was inferred from $\mathrm{A} 1$ as its mother, but its farther could not be identified successfully. The male helper $\mathrm{C} 3$ was inferred the offspring of the dominant female $\mathrm{C} 1$ and male $\mathrm{J} 1$ from another family. The male helper F2 was inferred from A2. The male helper G4 was from farther G3 in the family. Due to lack of the breeding pair, the male helper H1 was not inferred for its genetic parent. However, the helper was not observed in families $\mathrm{D}, \mathrm{E}, \mathrm{I}$, and $\mathrm{J}$ in the field. The parentages of helpers in breeding group were illustrated in Figure 1.

\section{Relatedness}

The mean relatedness of the whole wild population was $0.10269 \pm 0.02527$, and the relatedness of the individual pairs ranged from 0 to 0.9969 . The mean relatedness of nine females in the breeding population was estimated to be $0.08554 \pm 0.01041$; the mean relatedness of 20 males was estimated to be $0.10243 \pm 0.02838$. Theoretically, the mean $r$ coefficients of first-order, second-order and third-order kinships were $0.5,0.25$ and 0.125 , respectively (Blouin et al., 1996). In the actual research, the $r$ value was calculated based on the microsatellite data which usually fluctuated around the theoretical value. Referring to the relevant, we set the mean value of 0.1875 as the threshold $r$ for relatedness, which was between the second-order and third-order thresholds (Csilléry et al., 2006; Zhou et al., 2015). For the population with 29 individuals, $r$ values of 406 pairwise were calculated, among which, 81 pairs had $r>0.1875$. This indicated that the individual pairs with kinship were up to $19.95 \%$. Both A1 and B3 exhibit seven related individuals which were the largest number. In valid parent-offspring, the mean relatedness between mother and offspring was 0.4786 (ranged from 0.3323 to 0.9720 ), and the mean relatedness between father and offspring was 0.5149 (ranged from 0.3333 to 0.9056 ) (Supplementary Table SII). In addition, the mean relatedness between candidate father and mother was 0.1361 (ranged from 0.0091 to 0.4169 ), which was lower than the threshold value of 0.1875 (Supplementary Table SII). The mean relatedness of each family ranged from 0.00523 to 0.40450 , and the mean relatedness between different families ranged from 0 to 0.39127 (Supplementary Table SIII). Families with kinship include A-F, A-H, F-J and G-I.

\section{DISCUSSION}

\section{Effectiveness of screened microsatellite loci}

Tetra-nucleotide microsatellite markers with high polymorphism and short amplified fragment (less than
$300 \mathrm{bp}$ ) have been an ideal choice in forensic individual identification (Hochmeister et al., 1995). Different from previously isolated di-nucleotide and tri-nucleotide microsatellite loci (Wu et al., 2010; Yan et al., 2011), we screened a batch of tetra-nucleotide microsatellite markers for the first time in this study. The 17 loci screened exhibited high polymorphism and resolution in paternity identification with mean PIC of $0.566(>0.50)$ (Botstein et al., 1980). CPE (the combined probability of exclusion) value, an important index in determining genetic parent of an offspring (Sherman et al., 2004), has been successfully used in paternity test for many species (e.g., Crocodylus porosus: Isberg et al., 2004; Ursusarctos: Itoh et al., 2012; Ailuropoda melanoleuca: Huang et al., 2015). However, CPE value was influenced by the number of loci genotyped and heterozygosity of each locus. Our results based on 17 loci (98.84\% CPE1 and 99.98\% CPE2) showed very similar CPE indices with those studies mentioned above and the value of CPE2 was up to the standard of international human paternity testing (CPE $\geq 99.73 \%$ ) (Huang et al., 2015). These indicated that the screened microsatellite markers possessed high resolution and effectiveness in paternity testing.

\section{Helper resource}

Parent assignment indicated that seven helpers existed in six families (A, B, C, F, G and H). It was $3 / 7$ cases where helpers were related to the breeding pair, and 4/7 cases where helpers were unrelated. In the former cases, two helpers were related to dominant female (e.g. A, C) and another was related to dominant male (e.g. G). Obviously, helper resource in $T$. szechenyii was diverse which was very different from most of other cooperatively breeding birds (Double et al., 2005; Woxvold and Magrath, 2008; Beck et al., 2008; Koenig and Walters, 2016). For the majority of species, cooperative groups form when offspring from one brood remained on their natal territory to help raising younger relatives (Cockburn, 2006). Otherwise, this situation was consistent with the conclusion within a review which demonstrated that a surprisingly large number of cooperatively breeding species live in social groups that regularly include non-kin (Riehl, 2013). Although both female and male helpers had been detected in $T$. szechenyii, male helpers were distinctly more than the females (six times), which was consistent with many other cooperative breeding birds (Koenig et al., 1996). The sex difference of helper composition could be explained by sex-biased dispersal (see below).

In terms of evolution, the diversity of helper resource might be powerfully explained by the classical kin-selection hypothesis that inclusive fitness benefits was gained by close relatives of the breeders (Hamilton, 
1964), or by ecological limit hypothesis that the helper gave up the independent reproduction opportunity because of restriction from external habitat or environmental effect (Wang and $\mathrm{Lu}, 2011$ ). The traditional view of avian cooperative breeding involved two main evolution routes: via delayed dispersal of offspring, which leaded to the formation of family groups in which kin selection played a major role in promoting cooperation; or, less commonly, via competition for reproduction by unrelated individuals, which leaded to the formation of cooperatively polygamous groups in which all adults potentially reproduce (Hatchwell, 2009). T. szechenyii was restricted in high altitude mountains with cold climate, limited food resources and a large number of predators. Moreover, previous studies had showed that there was a limited selection of nest address and low reproductive success rate of T. szechenyii (Yang et al., 2009). To a certain extent, the dispersal of the birdlings was limited by the special requirements of habitat, and foreign helpers also can help the breeding pairs to take care of the offspring. This pattern suggested that the direct fitness benefits, specifically increasing survival, territory inheritance and access to current or future mating opportunity, lied in cooperative breeding groups.

\section{Inbreeding}

The offspring of delay dispersal and stay in the nest might lead to a risk of inbreeding (Blackmore and Heinsohn, 2008). A case of inbreeding was detected in family $\mathrm{C}$ in $T$. szechenyii. Parent tests indicated that $\mathrm{C} 3$, a male helper of delay dispersal, participated in the reproduction of $\mathrm{C} 2, \mathrm{C} 5$ and C6 (Table III). Moreover, C3 and its own female parent $\mathrm{C} 1$ was inferred to be genetic parent of the offspring $\mathrm{C} 2$, indicating $\mathrm{C} 2$ was the offspring of inbreeding between $\mathrm{C} 1$ and $\mathrm{C} 3$. The relatedness ( $\mathrm{r}$ ) between $\mathrm{C} 1$ and $\mathrm{C} 3$ was close to 0.5 , which also indicated that they were directly related (Full sibling) (Blouin et al., 1996). Interestingly, the other offspring except $\mathrm{C} 2$ had different genetic-female parent B3. Obviously, the female parent of the reproductive pair changed from $\mathrm{C} 1$ to $\mathrm{B} 3$, which may be explained by its elimination led by inbreeding or death.

Generally, the proportion of individuals with kinship relationship in a natural population is less than $10 \%$ (Csilléry et al., 2006). However, the proportion of the wild population in this study was up to $19.95 \%$ (see above), and relatively large numbers of individuals and families were detected to be related. All of the results suggested the existence of high inbreeding risk. Inbreeding may be a form of cost of reproduction when reproduction pair benefited from the cooperative breeding system (Blackmore and Heinsohn, 2008; Du and Lu, 2009). In other cooperatively breeding birds, extra-group mating could increase inbreeding risk, as individuals often demonstrate restricted natal dispersal that could result in a high concentration of relatives in the immediate neighborhood of the natal territory (Harrison et al., 2013).

\section{Extra-group paternity}

A large number of studies indicated that cuckolded mating widely existed in avian (Griffith et al., 2002; Arnold et al., 2005; Du and Lu, 2009). In fact, most birds were not strictly monogamous, and cooperative breeding species were no exception (Berg, 2005; Townsen et al., 2009). Based on analyses of the paternity of 37 cooperatively breeding bird species, Kingma et al. (2010) found extra-group paternity (EGP) phenomenon detected in approximately $70 \%$ of these species. In this study, the EGP appeared in family $\mathrm{C}$. The breeding pair of patriarchy was shared by $\mathrm{J} 1$ from another family and the offspring of C3. The EGP was enjoyed by the male helper who had affinities with the dominant male. This behavioral tendency might reduce the likelihood that the female would seek other EGP, thereby increasing the inclusive fitness (Du and Lu, 2009). This might also be explained by that the cooperative breeding could be a reproductive strategy to resist the EGP.

\section{Sex-biased dispersal}

It is generally recognized that the more distant relationship the individuals with the same sex have, the more possibility they spread (Goudet et al., 2002; Cutrera et al., 2005). The relationships between male individuals is closer than that of females, the males tend to be more concentrated and homesick (Wang and Lu, 2011). In this study, the mean relatedness between 9 females $(\mathrm{r}=0.0855)$ was less than that of the 20 males $(r=0.1024)$, indicating the presence of female-biased dispersal in T. szechenyii. Female-biased dispersal was very common in other birds (Koenig et al., 1996), and it might be explained by sexual reproduction strategy. Male birds often took "safeguard resources to attract the opposite sex" reproductive strategy, while the females chose reproductive opportunities and measured quality of males by dispersal (Greenwood, 1980; Clarke, 1997). The results of this study preliminarily revealed the characteristics of female-biased dispersal in $T$. szechenyii.

\section{CONCLUSION}

The cooperative breeding of Tetraophasis szechenyii is a rare and important instance in Galliformes. Using the next-generation sequencing, we firstly screened a batch of tetra-nucleotide microsatellite loci with high polymorphism and resolution. Based on a series of analyses 
for a wild population of $T$. szechenyii, the characteristics of cooperative breeding of this bird could be concluded: 1) helpers might be one or more within a family, and they were either philopatric offspring, or immigrated individuals from the other families, or both; 2) both sexes could be helper, but male helpers were obviously more than females; 3) T. szechenyii female-biased dispersal pattern and 4) inbreeding and extra-group paternity (EGP) were present in some families.

\section{ACKNOWLEDGMENTS}

This work was supported by the National Natural Science Foundation of China (31172105); and the Funding for research projects for the Sichuan Provincial Department of Education (16ZB0325). We appreciate N. Yang, B. Li and L. Dou for collecting samples. M. Fang and R. Xiao provided with assistance in laboratory work. L.M. Du is acknowledged for his assistance in data analyses.

\section{Supplementary material}

There is supplementary material associated with this article. Access the material online at: https://dx.doi. org/10.17582/journal.pjz/20191127131105

\section{Statement of conflict of interest}

The authors have declared no conflict of interest.

\section{REFERENCES}

Arnold, K., Owens, I. and Goldizen, A., 2005. Division of labour within cooperatively breeding groups. Behaviour, 142: 1577-1590. https://doi. org/10.1163/156853905774831927

Beck, N.R., Peakall, R. and Heinsohn, R., 2008. Social constraint and an absence of sex-biased dispersal drive fine scale genetic structure in white winged choughs. Mol. Ecol., 17: 4346-4358. https://doi. org/10.1111/j.1365-294X.2008.03906.x

Berg, E.C., 2005. Parentage and reproductive success in the white-throated magpie-jay, Calocitta formosa, a cooperative breeder with female helpers. Anim. Behav., 70: 375-385. https://doi.org/10.1016/j. anbehav.2004.11.008

Blackmore, C.J. and Heinsohn, R., 2008. Variable mating strategies and incest avoidance in cooperatively breeding grey-crowned babblers. Anim. Behav., 75: 63-70. https://doi.org/10.1016/j. anbehav.2007.04.010

Blouin, M.S., Parsons, M., Lacaille, V. and Lotz, S., 1996. Use of microsatellite loci to classify individuals by relatedness. Mol. Ecol., 5: 393-401. https://doi.
org/10.1111/j.1365-294X.1996.tb00329.x

Botstein, D., White, R.L., Sholnick, M. and Davis, R.W., 1980. Construction of a genetic linkage map in man using restriction fragment length polymorphisms. Am. J. Hum. Genet., 32: 314-331.

Brown, J., 1987. Helping and communal breeding in birds: Ecology and evolution. Princeton Univeristy Press, Princeton. https://doi.org/10.1515/9781400858569

Canestrari, D., Marcos, J. and Baglione, V., 2008. Reproductive success increases with group size in cooperative carrion crows, Corvus corone corone. Anim. Behav., 75: 403-416. https://doi. org/10.1016/j.anbehav.2007.05.005

Clarke, A.L., 1997. Sex biases in avian dispersal: A reappraisal. Oikos, 79: 429-438. https://doi. org/10.2307/3546885

Cockburn, A., 2006. Prevalence of different modes of parental care in birds. Proc. R. Soc. B., 273: 13751383. https://doi.org/10.1098/rspb.2005.3458

Covas, R., Deville, A.S., Doutrelant, C., Spottiswoode, C.N. and Grégoire, A., 2011. The effect of helpers on the post fledging period in a cooperatively breeding bird, the sociable weaver. Anim. Behav., 81: 121126. https://doi.org/10.1016/j.anbehav.2010.09.022

Csilléry, K., Johnson, T., Beraldi, D., Clutton-Brock, T., Coltman, D., Hansson, B., Spong, G. and Pemberton, J.M., 2006. Performance of markerbased relatedness estimators in natural populations of outbred vertebrates. Genetics, 173: 2091-2101. https://doi.org/10.1534/genetics.106.057331

Cutrera, A., Lacey, E. and Busch, C., 2005. Genetic structure in a solitary rodent (Ctenomys talarum): implications for kinship and dispersal. Mol. Ecol., 14: 2511-2523. https://doi.org/10.1111/j.1365294X.2005.02551.x

Du, B. and Lu, X., 2009. Bi-parental vs. cooperative breeding in a passerine: Fitness-maximizing strategies of males in response to risk of extra-pair paternity? Mol. Ecol., 18: 3929-3939. https://doi. org/10.1111/j.1365-294X.2009.04336.x

Double, M.C., Peakall, R., Beck, N.R. and Cockburn, A., 2005. Dispersal, philopatry and infidelity: Dissecting local genetic structure in superb fairywrens (Malurus cyaneus). Evolution, 59: 625-635. https://doi.org/10.1111/j.0014-3820.2005.tb01021.x

Ekman, J. and Ericson, P., 2006. Out of Gondwanaland: The evolutionary history of cooperative breeding and social behaviour among crows, magpies, jays and allies. Proc. biol. Sci., 273: 1117-1125. https:// doi.org/10.1098/rspb.2005.3431

Goudet, J., Perrin, N. and Waser, P., 2002. Tests for sexbiased dispersal using bi-parentally inherited genetic 
markers. Mol. Ecol., 11: 1103-1114. https://doi. org/10.1046/j.1365-294X.2002.01496.X

Greenwood, P.J., 1980. Mating systems, philopatry and dispersal in birds and mammals. Anim. Behav., 28: $\quad 1140-1162$. https://doi.org/10.1016/S00033472(80)80103-5

Griffith, S., Owens, I. and Thuman, K., 2002. Extra pair paternity in birds: a review of interspecific variation and adaptive function. Mol. Ecol., 11: 2195-2212. https://doi.org/10.1046/j.1365-294X.2002.01613.x

Griffiths, R., Daan, S. and Dijkstra, C., 1996. Sex identification in birds using two CHD genes. Proc. R. Soc. Lond. B. Biol., 263: 1251-1256. https://doi. org/10.1098/rspb.1996.0184

Hale, A., 2006. Group living in the black-breasted woodquail and the use of playbacks as a survey technique. Condor, 108: 107-119. https://doi.org/10.1093/ condor/108.1.107

Hamilton, W., 1964. The genetical evolution of social behaviour I and II. J. Theor. Biol., 7: 1-52. https:// doi.org/10.1016/0022-5193(64)90039-6

Handley, L., Ceplitis, H. and Ellegren, H., 2004. Evolutionary strata on the chicken $\mathrm{Z}$ chromosome: Implications for sex chromosome evolution. Genetics, 167: 367-376. https://doi.org/10.1534/ genetics.167.1.367

Harrison, X.A., York, J.E., Cram, D.L. and Young, A.J., 2013. Extra-group mating increases inbreeding risk in a cooperatively breeding bird. Mol. Ecol., 22: 57005715. https://doi.org/10.1111/mec. 12505

Hatchwell, B.J., 2009. The evolution of cooperative breeding in birds: kinship, dispersal and life history. Phil. Trans. R. Soc. B., 364: 3217-3227. https://doi. org/10.1098/rstb.2009.0109

Hochmeister, M.N., Budowle, B., Borer, U.V., Rudin, O., Bohnert, M. and Dirnhofer, R., 1995. Confirmation of the identity of human skeletal remains using multiplex PCR amplification and typing Kits. J. Forensic. Sci., 40: 701-705. https://doi.org/10.1520/JFS13855J

Huang, J., Li, Y., Du, L.M., Yang, B., Shen, F.J., Zhang, H.M., Zhang, Z.H., Zhang, X.Y. and Yue, B.S., 2015. Genome-wide survey and analysis of microsatellites in giant panda (Ailuropodamelanoleuca), with a focus on the applications of a novel microsatellite marker system. BMC Gnomics, 16: 1-12. https://doi. org/10.1186/s12864-015-1268-Z

Isberg, S.R., Chen, Y., Barker, S.G. and Moran, C., 2004. Analysis of microsatellites and parentage testing in saltwater crocodiles. J. Hered., 95: 445-449. https:// doi.org/10.1093/jhered/esh067

Itoh, T., Sato, Y., Kobayashi, K., Mano, T. and Iwata, R., 2012. Effective dispersal of brown bears (Ursus arctos) in eastern Hokkaido, inferred from analyses of mitochondrial DNA and microsatellites. Mamm. Study, 37: 29-41. https://doi.org/10.3106/041.037.0104

Jamieson, A. and Taylor, C., 1997. Comparisons of three probability formulae for parentage exclusion. Anim. Genet., 28: 397-400. https://doi.org/10.1111/j.13652052.1997.00186.x

Kalinowski, S., Taper, M. and Marshal, T., 2007. Revising how the computer program CERVUS accommodates genotyping error increases success in paternity assignment. Mol. Ecol., 16: 1099-1106. https://doi. org/10.1111/j.1365-294X.2007.03089.x

Kingma, S.A., Hall, M.L., Arriero, E. and Peters, A., 2010. Multiple benefits of cooperative breeding in purplecrowned fairy-wrens: a consequence of fidelity? $J$. Anim. Ecol., 79: 757-768. https://doi.org/10.1111/ j.1365-2656.2010.01697.x

Koenig, W.D., Van, V.D. and Hooge, P.N., 1996. Detectability, philopatry, and the distribution of dispersal distances in vertebrates. Trends Ecol. Evol., 11: 514. https://doi.org/10.1016/S01695347(96)20074-6

Koenig, W.D. and Walters, E.L., 2016. Provisioning patterns in the cooperatively breeding acorn woodpecker: does feeding behaviour serve as a signal? Anim. Behav., 119: 125-134. https://doi. org/10.1016/j.anbehav.2016.06.002

Ligon, J. and Burt, D., 2004. Evolutionary Origins. In: Ecology and evolution of cooperative breeding in birds (eds. W.D. Koenig and J.L. Dickinson). Cambridge University Press, Cambridge, UK, pp. 5-34. https:// doi.org/10.1017/CBO9780511606816.002

Lu, X. and Zheng, G., 2005. Cooperative young caring behaviour in a hybrid population of white and Tibetan eared-pheasants in Tibet. Ardea, 93: 17-24.

Mackinnon, J.R. and Phillipps. K., 2000. A field guide to the birds of China. Oxford University Press, New York, USA.

Madge, S. and McGowan, P., 2002. Pheasants, partridges and grouse. Christopher Helm, London. pp. 1-488.

Marshall, T.C., Slate, J., Kruuk, L.E.B. and Pemberton., J.M., 1998. Statistical confidence for likelihoodbased paternityinference in natural populations. Mol. Ecol., 7: 639-655. https://doi.org/10.1046/j.1365294x.1998.00374.x

Meade, J. and Hatchwell, B.J., 2010. No direct fitness benefits of helping in a cooperative breeder despite higher survival of helpers. Behav. Ecol., 21: 11861194. https://doi.org/10.1093/beheco/arq137

Michod, R. and Hamilton, W., 1980. Coefficients of relatedness in sociobiology. Nature, 288: 694-697. https://doi.org/10.1038/288694a0

Pravosudova, E.V., Grubb, T.C. and Parker, P.G., 2001. The influence of kinship on nutritional condition 
and aggression levels in winter social groups of Tufted Titmice. Condor, 103: 821-828. https://doi. org/10.1093/condor/103.4.821

Preston, S.A.J., Briskie, J.V., Burke, T. and Hatchwell, B.J., 2013. Genetic analysis reveals diverse kindirected routes to helping in the rifleman Acanthisitta chloris. Mol. Ecol., 22: 5027-5039. https://doi. org/10.1111/mec. 12448

Raymond, M. and Rousset, F., 1995. Genepop (Version 1.2): Population genetics software for exact tests and ecumenicism. J. Hered., 86: 248-249. https://doi. org/10.1093/oxfordjournals.jhered.a111573

Riehl, C., 2013. Evolutionary routes to non-kin cooperative breeding in birds. Proc. R. Soc. B., 280: 2013245. https://doi.org/10.1098/rspb.2013.2245

Sherman, G., Kachman, S., Hungerford, L., Rupp, G.P., Fox, C.P., Brown, M.D., Feuz, B.M., Holm, T.R., 2004. Impact of candidate sire number and sire relatedness on DNA polymorphism-based measures of exclusion probability and probability of unambiguous parentage. Anim. Genet., 35: 220-226. https://doi.org/10.1111/j.1365-2052.2004.01143.x

Townsend, A.K., Clark, A.B., McGowan, K.J. and Lovette, I.J., 2009. Reproductive partitioning and the assumptions of reproductive skew models in the cooperatively breeding American crow. Anim. Behav., 77: 503-512. https://doi.org/10.1016/j. anbehav.2008.10.030

Van Oosterhout, C., Hutchinson, W.F., Wills, D.P.M. and Shipley, P., 2004. MICRO-CHECKER: Software for identifying and correcting genotyping errors in microsatellite data. Mol. Ecol. Notes, 4: 535-538. https://doi.org/10.1111/j.1471-8286.2004.00684.x

Vehrencamp, S. and Quinn, J., 2004. Joint laying systems. Pages 177-196 in Cooperative breeding in birds: Recent research and new theory (eds. W.D. Koenig and J. Dickinson). Cambridge University Press. https://doi.org/10.1017/CBO9780511606816.012

Wang, C. and Lu, X., 2011. Female ground tits prefer relatives as extra-pair partners: Driven by kin selection? Mol. Ecol., 20: 2851-2863. https://doi. org/10.1111/j.1365-294X.2011.05070.x

Wang, J., 2011. Coancestry: a program for simulating, estimating and analysing relatedness and inbreeding coefficients. Mol. Ecol. Resour., 11: 141-145. https:// doi.org/10.1111/j.1755-0998.2010.02885.x

Woxvold, I.A. and Magrath, M.J.L., 2008. Sex-biases in the hatching sequence of cooperatively breeding apostle birds Struthidea cinerea. Evolution. Ecol., 22: 139-151. https://doi.org/10.1007/s10682-007-9163-y

Wu, A.L., Zhang, X.Y., Yang, N., Ran, J.H., Yue, B.S. and Li, J., 2010. Isolation and characterization of twenty dinucleotide microsatellite loci in the buff-throated partridge, Tetraophasis szechenyii conservation. Genet. Resour., 2: 85-87. https://doi.org/10.1007/ s12686-010-9187-4

Xu, Y., Yang, N., Zhang, K., Yue, B.S. and Ran, J.H., 2011. Cooperative breeding by buff-throated partridge Tetraophasis szechenyii: A case in the Galliformes. J. Ornithol., 152: 695-700. https://doi.org/10.1007/ s10336-011-0651-Z

Yan, M., Zhang, X., Yang, N., Yue, B. and Ran, J., 2011. Isolation and characterization of twelve polymorphic microsatellite loci in the buff-throated partridge (Tetraophasis szechenyii). Russ. J. Genet., 47: 277230. https://doi.org/10.1134/S1022795410081022

Yang, N., Xu, Y., Ran, J., Zhang, K., Yue, B. and Li, B., 2009. Notes on the breeding habits of the buffthroated partridge. Chi. J. Zool., 44: 48-51.

Yang, N., Moermond, T.C., Lioyd, H., Xu, Y., Dou, L., Zhang, K., Yue, B. and Ran, J., 2016. Effects of supplementary feeding on the breeding ecology of the buff-throated partridge in a Tibetan sacred site, China. PLoS One, 11: e0146568. https://doi.org/10.1371/ journal.pone. 0146568

Zeng, L., Rotenberry, J.T., Zuk, M., Pratt, T.K. and Zhang, Z., 2016. Social behavior and cooperative breeding in a precocial species: The Kalij pheasant (Lophura leucomelanos) in Hawaii. Auk., 133: 747-760. https:// doi.org/10.1642/AUK-15-227.1

Zhou, X., Yang, N., Yue, B.S., Ran, J.H. and Li, J., 2008. Sex identification in buff-throated partridge using PCR method. Sichuan J. Zool., 27: 645-647.

Zhou, Y.Y., Yang, W.J., Zhang, Y.G., Lu, H. and Liu, X., 2015. Genetic diversity and relatedness of the golden snub-nosed monkey provisioned group in Shennongjia National Natural Reserve. Acta Theriol. Sin., 3: 229-240. 